\title{
Effects of Rapid Tryptophan Depletion on Sleep Electroencephalogram and Mood in Subjects with Partially Remitted Depression on Bupropion
}

Lynn Evans, M.S., Shahrokh Golshan, Ph.D., John Kelsoe, M.D., Mark Rapaport, M.D., Kathryn Resovsky, R.N., Laura Sutton, R.N., and J. Christian Gillin, M.D.

Serotonin has been implicated in both sleep and mood regulation. When central serotonin was depleted with a tryptophan-free amino acid drink (TFD), some studies have reported that the antidepressant benefits were reversed in partially remitted patients treated with SSRIs. Other studies showed that the TFD increased rapid eye movement (REM) sleep in both normal males and in remitted depression patients on selective serotonin reuptake inhibitors (SSRIs) without affecting mood. In this study, we administered a TFD to patients with remitted depression who were being treated with bupropion, an antidepressant whose mechanism of action apparently does not affect the serotonin system. We hypothesized that the TFD would increase the propensity for REM sleep without affecting depression ratings. Eight partially remitted depression subjects on bupropion were administered a TFD and a control drink containing tryptophan in double-blind, random order on separate days. The effects of these drinks were monitored with sleep electroencephalograms, mood ratings, and plasma tryptophan measures comparing baseline, TFD, and control nights. The TFDs reduced REM latency and stage 2 percent and increased REM time and percent. Subjective measures of elation, vigor, and friendliness significantly decreased on both TFD and control drinks but depression ratings did not. Plasma levels of tryptophan decreased with the TFD. Although the TFD altered REM sleep, certain mood measures, and plasma tryptophan levels, no relapses into depression were seen with our subjects. Bupropion alone did not affect sleep measures.

[Neuropsychopharmacology 27:1016-1026, 2002] (C) 2002 American College of Neuropsychopharmacology. Published by Elsevier Science Inc.
KEY WORDS: Serotonin; Electroencephalography; REM Sleep; Mood Disorders

From the Department of Psychiatry, University of California, San Diego and the Mental Health Clinical Research Center, Veterans Affairs San Diego Health Care System (LE, SG, JK, MR, CR, JCG), and the University of California, San Diego Neuroscience Graduate Program (LE).

Address correspondence to: J. Christian Gillin, M.D., University of California, San Diego, Department of Psychiatry, Veterans Affairs Medical Center (116-A), 3350 La Jolla Village Drive, San Diego, CA 92161. Tel.: (858) 534-2137; jgillin@ucsd.edu

Received January 9, 2002; revised April 13, 2002; accepted April $18,2002$.

Online publication: $4 / 23 / 02$ at www.acnp.org/citations/ Npp042302288.
Serotonin (5-hydroxytryptamine; 5-HT) has long been implicated in the pathophysiology of depression as well as in the sleep and mood abnormalities associated with depression (Maes and Meltzer 1995). Specifically, deficiencies in 5-HT levels or in cellular responses to 5-HT neurotransmission are thought to be involved in depression. In support of this idea, deficiencies in 5-HT neurotransmission in various projections from the raphe nucleus can at least partially explain many of the common abnormalities seen in depression such as a depressed mood, decreased interest and pleasure, decreased appetite, and insomnia (Stahl 2000). Also commonly seen in depression are reduced rapid eye 
movement (REM) latency (RL; time from sleep onset till the first REM period), increased REM percentage (REM\%; percent of total night's sleep), and increased REM density (RD; ocular activity during REM on a scale of $0-4$ per $30 \mathrm{~s}$; Benca et al. 1992). Again, a 5-HT deficiency can explain these abnormalities since 5-HT neurotransmission is known to inhibit REM sleep (McGinty and Drucker-Colin 1982; McCarley 1982; Jones 1991; Luebke et al. 1992).

The rate of 5-HT synthesis is limited by the availability of its amino acid precursor, tryptophan. Rapid depletion of plasma tryptophan levels by administration of a tryptophan-free amino acid drink (TFD) depletes central 5-HT levels (Biggio et al. 1974; Moja et al. 1988). See Moore et al. (2000) for a recent review of the TFD literature.

Consistent with the hypothesis that 5-HT inhibits REM sleep, Bhatti et al. (1998) found that a TFD decreased REM latency and increased REM\% in normal male subjects. Voderholzer et al. (1998) found a significant increase in RD in 12 healthy subjects after TFD administration but saw no other significant REM changes. A study by Moore et al. (1998) found reduced RL and stage 2 percent (S2\%) and increased REM $\%$ and RD after TFD administration in fully remitted depression patients on selective serotonin reuptake inhibitors (SSRIs). Additionally, in four patients treated with the monoamine oxidase inhibitor (MAOI), phenelzine, Landolt et al. (2000) showed increased REM time and REM\% after TFD administration.

With regard to mood, TFD studies have had mixed results when tested in normal subjects. One TFD study showed normal males having significantly increased scores on a depression scale, the Multiple Affect Adjective Checklist (MAACL), after TFD administration (Young et al. 1985). Benkelfat et al. (1994) also found decreased mood on the Profile of Mood States (POMS) in six out of 20 of his healthy male subjects with a multigenerational history of affective disorder. Additionally, Klaassen et al. (1999) found that TFD administration lowered mood in both subjects with and without a family history of affective disorders with the mood changes being significantly more evident in those with a family history. Ellenbogen et al. (1996) showed that healthy female subjects had significantly lower scores after a TFD on four of six scales on the bipolar form of the POMS including the depression scale. However, Ellenbogen et al. (1999) showed that normal females with a multi-generational family history of major affective disorders had no lowering of mood in response to a TFD. Quintin et al. (2001) showed a decline in mood as measured by the Hamilton Rating Scale for Depression (HRSD) and the Depressive Mood Scale in unaffected subjects with at least two bipolar relatives but no change in health controls without a family history of affective disorders. Along the same lines, normal males given a TFD in the
Bhatti et al. (1998) study showed no significant change on the depression subscale of the POMS. These subjects did, however, show significant decreases in the POMS elation, friendliness, and vigor subscales and significant increases in the confusion and tension subscales (Bhatti et al. 1998). Likewise, Abbott et al. (1992) showed no significant changes on the POMS with tryptophan depletion in normal volunteers.

TFDs have also had mixed results in remitted patients with depression. Delgado et al. (1990, 1991, 1999) found that $53-80 \%$ of partially remitted depressed patients on SSRIs suffered a "depressive relapse" after administration of a TFD. Another 10 patients on SSRIs in a study by Spillman et al. (2001) had significantly increased scores on the 6-item HRSD, the Hamilton Anxiety Rating Scale, and the Symptom Questionnaire Somatic Symptoms and Anxiety in response to a TFD. In a study by Bremner et al. (1997), seven out of 21 patients (some partially and some fully remitted) suffered a "depressive relapse" after TFD administration. In contrast, Moore et al. (1998) did not show significantly increased mean depression ratings on the POMS or the 19-item HRSD but did find lower mood ratings on the POMS elation, friendliness, and vigor subscales and a higher rating on confusion after fully remitted patients on SSRIs were given a TFD. Also in contrast to the previously mentioned studies by Delgado, Spillman, and Bremner, a study by Leyton et al. (1997) revealed that medication-free patients in remission from depression had no change in mood in response to a TFD. In another study by Leyton et al. (2000), however, medication-free, remitted patients with a family history of psychiatric disorders had significantly greater mood-lowering responses to TFD than remitted patients without the family history. Most surprisingly, in a study by Neumeister et al. (1998), TFDs in patients who responded to total sleep deprivation prevented depressive relapse after the recovery night in most patients.

The current study examines the effects of the antidepressant bupropion on sleep and of a TFD on partially remitted depressed outpatients being treated with bupropion. Bupropion's mechanism of action as an antidepressant is not completely understood. In synaptosomal preparations, bupropion inhibits dopamine (DA) reuptake weakly but somewhat selectively and inhibits norepinephrine (NE) reuptake with half that strength (Ferris and Cooper 1993). When bupropion is chronically administered, in vivo microdialysis reveals increased extracellular dopamine in the nucleus accumbens (Nomikos et al. 1992). Chronic administration of bupropion also decreases tyrosine hydroxylase reactivity in the locus ceruleus of the rat (Nestler et al. 1990). Likewise, bupropion reduces firing rates of NE neurons in the locus ceruleus in a dose-dependent manner (Cooper et al. 1994), and at higher doses, it reduces firing in DA neurons in A9 and A10 of the rat brain (Ferris and 
Cooper 1993). In depressed patients, bupropion enhances 6-hydroxy melatonin levels, a marker of functional activity in the NE system (Golden et al. 1988). Furthermore, bupropion administration can downregulate NMDA receptors (Paul et al. 1994). Bupropion does not have an apparent effect on the 5-HT system (Cooper et al. 1994; Feighner 1999; Horst and Preskorn 1998; Stahl 1997). For a more complete review of bupropion's mechanism of action, see Ascher et al. (1995).

Delgado et al. (1991) reported the effects of TFDs on two patients in clinical remission while on bupropion. Neither patient suffered a "depressive relapse" as a result of tryptophan depletion. With regard to sleep, Nofzinger et al. (1995) previously reported bupropion to significantly increase REM time and REM\% in seven remitted depression patients on bupropion when compared with a before treatment baseline. A significant decrease in RL was also seen, when two bupropion nonresponders were added to the data pool. No other reports on bupropion's effects on sleep or of a TFDs effects on bupropion treated patients have been published at this time.

When designing this study, we had three main questions in mind: (1) How does bupropion affect sleep measures? (2) How does a TFD affect sleep measures in partially remitted depressed patients on bupropion? and (3) How does a TFD affect the depression and mood ratings of bupropion treated patients? Regarding the first question, we predicted that bupropion would increase REM time and REM $\%$ based on the findings of Nofzinger et al. (1995). Our expectations for question 2 were to see a significant decrease in RL and S2\%, a significant increase in REM time and REM\%, but no significant change in RD. We based these expectations upon what is known of 5-HT's role in inhibiting REM sleep and our previous results in other populations (Bhatti et al. 1998; Moore et al. 1998; Landolt et al. 2000). For question 3, based on our previous studies in normal volunteers and euthymic patients treated with SSRIs, we predicted that the TFD would not significantly alter depression ratings (the depression subscale of the POMS and the 19-item HRSD). Nevertheless, we expected the scores on the vigor, elation, friendliness, tension, and confusion subscales of the POMS questionnaire to significantly worsen with the TFD compared with the control drink. By answering these three questions, we hoped to gain insight into the physiology of depression and sleep and into bupropion's mechanism of action.

\section{METHODS}

\section{Subjects}

To be eligible, subjects had to have a diagnosis of major depressive disorder following a formal structured diagnostic psychiatric interview (Structured Clinical Inter- view for DSM-IV; SCID), be drug free for at least two weeks ( $>5$ weeks for fluoxetine), be free of other recent or current major comorbid medical, psychiatric, or substance abuse disorders, and have a score above 12 on the 17-item HRSD (HRSD-17-a modified version of the 24-item HRSD that only uses the first 17 items; Hamilton 1967) for at least two weeks. We chose the HRSD-17 for our criteria, as opposed to other forms of the HRSD, due to its widespread use in TFD studies by other researchers. Seventeen subjects participated in this research protocol as part of a double-blind study of bupropion and sertraline. Nine were placed on sertraline and eight were placed on bupropion. We will only be considering the subjects placed on bupropion in this paper. These eight subjects (mean age \pm SD; $45.5 \pm 10.4$ years) met all inclusion criteria (see below) and completed the TFD portion of the study. Six of these subjects were male and two were female (see Table 1 for a more complete summary of subject information). Final diagnoses were made at a weekly diagnostic conference. All subjects were paid for their participation and gave written informed consent to participate in the study after receiving both written and verbal explanations of the protocol. The protocol used was approved by the UCSD and Veterans Affairs Human Subjects Committees.

Inclusion criteria for participation in the TFD challenges were the following: (1) a history of a major depressive episode in full to partial remission for at least two weeks by the clinical judgement of the patient and a psychiatrist; (2) on-going treatment with only bupropion and no other major psychotropic or hypnotic medications (see Table 1 for duration of treatment details); and (3) a reduction in score $\geqslant 40 \%$ on the HRSD- 17 compared with the pre-treatment scores.

\section{Procedures}

After a drug free interval of two weeks, subjects slept in the sleep laboratory for two nights before beginning bupropion treatment. The first of these nights was used to screen for sleep disorders and to allow for adaptation to the sleep lab. The second night was used to obtain drug-free baseline polysomnographic recordings (electroencephalogram (EEG), bilateral electrooculogram, chin electromyogram, and electrocardiogram).

Once a subject had been treated with bupropion and was in partial remission, subjects slept in the lab for four more nights. The first night was again used for adaptation and screening. The other three nights were for the bupropion baseline, TFD, and control polysomnographic recordings. Challenge nights were separated by at least $48 \mathrm{~h}$ and were done in random order for each subject along with the bupropion baseline night. Polysomnographic recordings were conducted on all nights from about 11:30 P.M. till about 6:30 A.M. 
Table 1. Demographic Information, Diagnoses, and Baseline HRSD-17 Scores of the Subjects

\begin{tabular}{|c|c|c|c|c|c|c|c|c|c|}
\hline $\begin{array}{l}\text { Subject } \\
\#\end{array}$ & Sex & $\begin{array}{l}\text { Age } \\
\text { (y) }\end{array}$ & $\begin{array}{c}\text { Weight } \\
\text { (kg) }\end{array}$ & $\begin{array}{c}\text { Primary } \\
\text { SCID } \\
\text { Diagnosis* }\end{array}$ & $\begin{array}{c}\text { Secondary } \\
\text { SCID } \\
\text { Diagnosis** }\end{array}$ & $\begin{array}{c}\text { Weeks } \\
\text { on } \\
\text { Drug } \ddagger\end{array}$ & $\begin{array}{l}\text { Dose at Time } \\
\text { of TFD }\end{array}$ & $\begin{array}{l}\text { HRSD-17/-24 } \\
\text { before } \\
\text { Drug }\end{array}$ & $\begin{array}{c}\text { HRSD-17/-24 } \\
\text { before } \\
\text { TFD }\end{array}$ \\
\hline 1 & M & 30 & 113.0 & Bipolar II D & None & 8 & $200 \mathrm{mg}$ bid & $12 / 14$ & $3 / 3$ \\
\hline 2 & M & 43 & 91.5 & MDD (S) & None & 11 & $150 \mathrm{mg}$ tid & $15 / 22$ & $7 / 7$ \\
\hline 3 & M & 51 & 77.0 & MDD (S) & None & 6 & $150 \mathrm{mg}$ bid & $15 / 19$ & $9 / 9$ \\
\hline 4 & M & 54 & 94.5 & MDD (R) & ADFR & 5 & $150 \mathrm{mg}$ bid & $21 / 26$ & $4 / 4$ \\
\hline 5 & $\mathrm{~F}$ & 57 & 84.8 & MDD (R) & None & 9 & $150 \mathrm{mg}$ tid & $19 / 23$ & $9 / 9$ \\
\hline 6 & M & 37 & 73.6 & MDD (S) & None & 7 & $150 \mathrm{mg}$ bid & $15 / 16$ & $2 / 2$ \\
\hline 7 & $\mathrm{~F}$ & 56 & 68.2 & MDD (R) & None & 6 & $200 \mathrm{mg}$ bid & $15 / 24$ & $9 / 10$ \\
\hline 8 & M & 36 & 99.8 & MDD (R) & PTSD-FR & 7 & $200 \mathrm{mg}$ bid & $18 / 22$ & $9 / 11$ \\
\hline
\end{tabular}

${ }^{*}$ The primary SCID diagnoses are as follows: Bipolar II D, Bipolar II Depression; MDD (S), Major Depressive Disorder Single Episode; MDD (R), Major Depressive Disorder Recurrent

**The secondary SCID diagnoses are as follows: ADFR, Alcohol Dependence Full Remission; PTSD-FR, Posttraumatic Stress Disorder Full Remission

¥The number of weeks on bupropion before the tryptophan challenge with the TFD and control drinks was administered

A set schedule was followed during the TFD challenge and control days. At 2:30 P.M., mood ratings, a side effect assessment, and $10 \mathrm{~mL}$ of blood for tryptophan levels were obtained. At 3:00 P.M., either the TFD or control drink was administered in a double-blind, randomized, crossover fashion. At 10:30 P.M., mood ratings, a side effects checklist, and a blood sample were obtained. Then, from about 11:30 P.M. till about 6:30 A.M., polysomnographic recordings were taken during the subjects' time in bed (from "lights out" till "lights on"). At 7:00 A.M., mood ratings and a blood sample were obtained and a general sleep questionnaire was administered. This schedule is based on what we have used in previous TFD studies.

Polysomnographic recordings were visually scored in 30-s epochs by sleep technicians according to standard criteria (Rechtschaffen and Kales 1968). Interrater reliability among the technicians was tested regularly and was maintained at a level of 0.80 or greater for each sleep measure. Sleep variables are briefly defined as follows. Time in bed is the time in minutes from "lights out" until "lights on." Total sleep time (TST) is the time in bed minus any awake time. Sleep efficiency (SE) is the TST divided by the time in bed expressed as a percent. Sleep latency (SL) is the time in minutes from "lights out" until the first onset of stage 2 or REM sleep with no more than a minute of wakefulness within the first ten minutes. Wakefulness after sleep onset (WASO) is the time spent awake in bed after sleep onset in minutes. REM minutes is the total number of minutes spent in REM sleep. Stage 1 through $4 \mathrm{~min}$ (S1, S2, S3, and S4) is the amount of time spent in each stage, respectively. Dividing S1, S2, S3, and S4 by TST gives the stage 1 through 4 percents (S1\%, $\mathrm{S} 2 \%, \mathrm{~S} 3 \%$, and $\mathrm{S} 4 \%$ ). RL, REM\%, and RD were previously defined in the introduction.

Current mood was assessed in two ways. One way was by blinded raters $(k=0.82)$, using a modified 19item version of the HRSD (HRSD-19) that excludes items 4 through 6 (pertaining to sleep), item 16 (pertaining to weight change), and item 18 (pertaining to diurnal variation) from the 24-item HRSD (Hamilton 1967). The 24item HRSD would have been used, but the questions excluded to form the HRSD-19 make no sense when asked multiple times in one day. A second way that current mood was assessed was by having the patients complete the subjective POMS, a rating scale that describes current mood with eight subscales (McNair et al. 1981). A side effects checklist and general sleep questionnaire were also administered at the appropriate times.

Patients ate a low-tryptophan diet starting at dinner the night before administration of the TFD and control drinks. The diet contained $2300 \mathrm{kcal} / \mathrm{d}$ and $48 \mathrm{~g} / \mathrm{d}$ of protein but only $160 \mathrm{mg} / \mathrm{d}$ of tryptophan. The TFD contains 15 amino acids in the same proportion as human milk minus tryptophan, aspartic acid, and glutamic acid. The TFD mixture was made according to each subject's body weight at $85 \mathrm{~g}$ of amino acid mixture per $70 \mathrm{~kg}$ of person. This approach reduced the vomiting that was frequently induced in women when $100 \mathrm{~g}$ amino acid mixtures were given to everyone regardless of size (Bhatti et al. 1998). The control drink was made from the same amino acid mixture used in the individualized TFDs plus $4 \mathrm{~g}$ of tryptophan. Both the TFD and control were served with chocolate-flavored syrup in a $300 \mathrm{~mL}$ "slurry" with crushed ice. Methionine, cysteine, and arginine were given in blinded pill form (21 pills per TFD or control challenge) because of the bitterness and unpalatability they added to the drink. The blood samples of tryptophan were collected with EDTA, centrifuged, and frozen $\left(-80^{\circ} \mathrm{C}\right)$ until analysis. Free plasma tryptophan concentrations were determined using a modified fluorometric method (Denckla and Dewey 1967).

\section{Statistics}

For the before and after bupropion sleep measures, we used a simple repeated measures analysis of variance 
(ANOVA), and for both the sleep and mood measures when looking at the effects of the TFD, we used a repeated measures ANOVA with one within-subjects factor (pre-challenge baseline, TFD, and control). Because we had a very specific hypothesis regarding which sleep variables would be affected by TFD, we ran a separate ANOVA for those variables expected to significantly change. The results from the ANOVA for the other sleep variables are reported for those who may be interested. Pairwise ANOVAs were run on both sleep and mood variables shown to be significant in the repeated measures ANOVAs described above. Two-way ANOVA $(2 \times 3$ design $)$ with repeated measures was used to compare the differences in mood scores at various times on different days. For the tryptophan data, a repeated measures ANOVA with two within-subjects factors (Day - control and experimental; Time - 2:30 P.M., 10:30 P.M., and 7:00 A.M.) was used with the Tukey HSD as the post-hoc test. All data are expressed as means \pm SEM with $n=8$ unless otherwise specified. Level of significance was $\alpha$ equal to 0.05 .

\section{RESULTS}

\section{Sleep Measures}

Patients showed no significant change in sleep measures after treatment with bupropion for an average of seven weeks (while-on-bupropion baseline) compared with the drug-free pre-bupropion baseline (Table 2).

Table 2. Summary and Comparison of Sleep Measures before and during Bupropion Treatment

\begin{tabular}{lccc}
\hline $\begin{array}{l}\text { Sleep } \\
\text { Variable }\end{array}$ & $\begin{array}{c}\text { Before } \\
\text { Bupropion }\end{array}$ & $\begin{array}{c}\text { During } \\
\text { Bupropion }\end{array}$ & $\mathbf{F}_{\mathbf{1 , 1 5}}$ \\
\hline TST & $363 \pm 13$ & $343 \pm 22$ & 0.96 \\
SE & $87 \pm 1$ & $81 \pm 5$ & 2.49 \\
SL & $20 \pm 5$ & $32 \pm 13$ & 1.00 \\
WASO & $30 \pm 4$ & $45 \pm 13$ & 1.76 \\
S1 & $21 \pm 3$ & $20 \pm 2$ & 0.09 \\
S2 & $231 \pm 15$ & $205 \pm 14$ & 1.87 \\
S3 & $33 \pm 9$ & $27 \pm 6$ & 0.81 \\
S4 & $8 \pm 5$ & $12 \pm 6$ & 0.36 \\
REM & $70 \pm 6$ & $78 \pm 9$ & 0.68 \\
S1\% & $6 \pm 1$ & $6 \pm 1$ & 0.00 \\
S2\% & $64 \pm 3$ & $60 \pm 3$ & 0.90 \\
S3\% & $9 \pm 3$ & $8 \pm 2$ & 0.53 \\
S4\% & $2 \pm 1$ & $3 \pm 2$ & 0.48 \\
REM $\%$ & $19 \pm 2$ & $23 \pm 2$ & 2.67 \\
RL & $79 \pm 15$ & $78 \pm 11$ & 0.00 \\
RD & $1.8 \pm 0.3$ & $2.2 \pm 0.2$ & 4.93 \\
\hline
\end{tabular}

All data are expressed as means \pm standard error

TST, Total Sleep Time (min); SE, Sleep Efficiency; SL, Sleep Latency (min); WASO, Wakefulness After Sleep Onset (min); S1-S4, Stage 1-4 Minutes; REM, REM Minutes; S1\%-S4\%, Stage 1-4 Percentages; REM\%, REM Percentage; RL, REM Latency (min); RD, REM Density; NS, Not Significant
When comparing the TFD challenge, control, and while-on-bupropion baseline nights, however, significant changes were seen in RL $\left(\mathrm{F}_{2,14}=5.55, p=.02\right)$, REM time $\left(\mathrm{F}_{2,14}=7.32, p=.007\right), \mathrm{REM} \%\left(\mathrm{~F}_{2,14}=7.27\right.$, $p=.007)$, and $\mathrm{S} 2 \%\left(\mathrm{~F}_{2,14}=7.06, p=.008\right.$; see Figure 1$)$. Pairwise ANOVAs revealed that the TFD challenge night had a significantly reduced RL and S2\% when compared with the baseline $(p=.02$ and $p=.042$, respectively) and control nights ( $p=.046$ and $p=.015$, respectively) and that it had a significantly increased REM time and REM\% when compared with the baseline $(p=.001$ and $p=.01$, respectively) and control nights ( $p=.04$ and $p=.03$, respectively). See Table 3 for a summary of all other sleep measure results.

\section{Mood Measures}

Based on the HRSD-17, patients were significantly less depressed at the while-on-bupropion baseline compared with the drug-free, pre-bupropion baseline (6.5 \pm 1.1 versus $\left.16.3 \pm 1.0, \mathrm{~F}_{1,15}=55.74, p<.001\right)$. Five patients were judged to be in partial remission (HRSD-17 scores from 7 to 9 for at least two weeks) and three patients in near full remission (HRSD-17 scores from 2 to 4 for at least two weeks) before the TFD challenges. In Table 1, HRSD-17 scores from before bupropion treatment
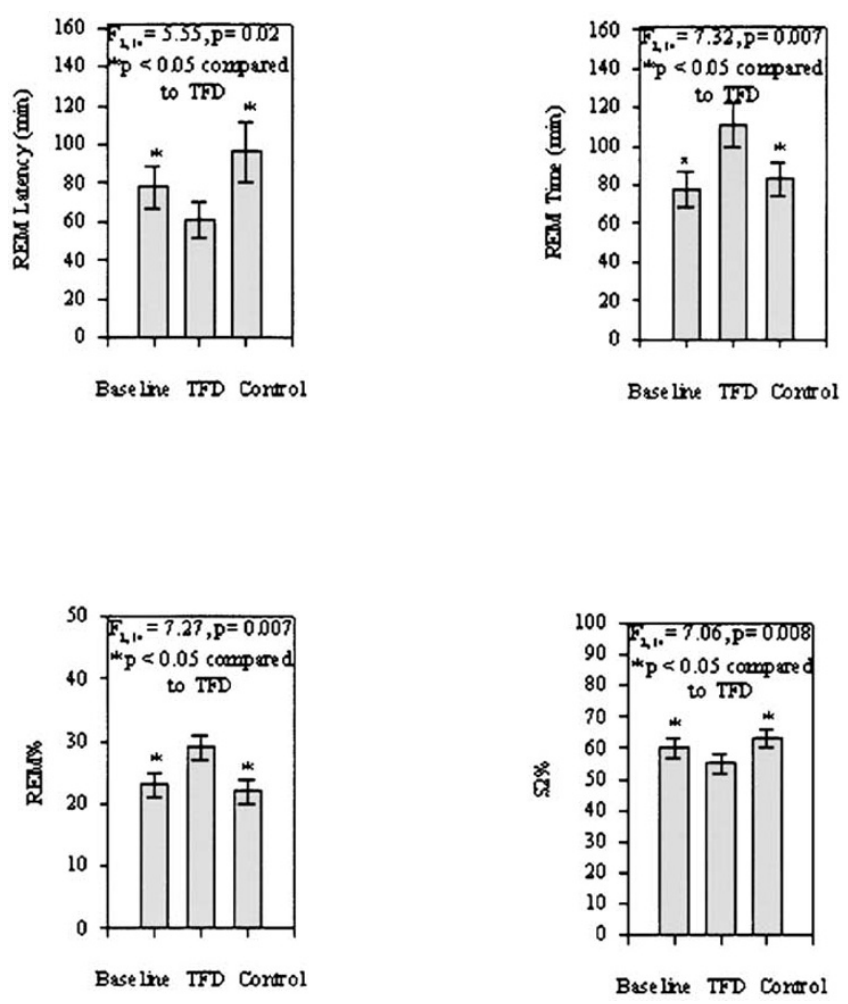

Figure 1. Graphs of average RL, REM Time, REM\%, and S2\% during the While-On-Bupropion Baseline, TFD, and Control Nights (values given are means \pm SEM, $\mathrm{n}=8$ ) 
and after reaching partial remission status are given for each subject.

During the TFD challenges, the HRSD-19 scores did not change significantly after administration of the TFD or control drink when compared with the while-on-bupropion baseline from the same time of day (10:30 P.M.). We also saw no "depressive relapses" according to the criteria either of Delgado (1990, 1991, 1999) or Bremner (1997). There were, however, significant changes in the POMS subscales of vigor $\left(\mathrm{F}_{2,14}=5.02, p=.02\right)$, elation $\left(\mathrm{F}_{2,14}=\right.$ $7.54, p=.006)$, and friendliness $\left(\mathrm{F}_{2,14}=5.44, p=.02\right)$ when comparing all three nights. In pairwise ANOVAs, the vigor, elation, and friendliness subscales all significantly decreased on both the TFD and control nights when compared with the baseline night. See Table 4 for a summary of the mood measures results.

When testing for diurnal variation during each of the two drink challenges, a 2-way ANOVA with day and time as the grouping factors showed no significant interaction effect for any of the mood ratings. There were also no significant changes when grouping only by day; however, there were some significant changes when grouping only by time. The POMS subscales of vigor and anger significantly decreased $\left(\mathrm{F}_{1,7}=6.47, p=.038\right.$; $\mathrm{F}_{1,7}=10.50, p=.014$, respectively) from the 2:30 P.M. to the 10:30 P.M. time point, and the POMS friendliness subscale significantly increased $\left(\mathrm{F}_{1,7}=6.46, p=.038\right)$ from the 10:30 P.M. to the 7:00 A.M. time point. There were no significant diurnal changes in HRSD-19 scores on either day (Table 5).

Our results showed that both the experimental and the control drinks significantly reduced the vigor, elation, and friendliness subscale scores on the POMS.

Table 3. Summary and Comparison of Sleep Measures on the While-On-Bupropion Baseline, TFD, and Control Nights

\begin{tabular}{lcccc}
\hline $\begin{array}{l}\text { Sleep } \\
\text { Variable }\end{array}$ & Baseline & TFD & Control & $\mathbf{F}_{2, \mathbf{1 4}}$ \\
\hline TST & $343 \pm 22$ & $387 \pm 13$ & $377 \pm 18$ & 2.36 \\
SE & $81 \pm 5$ & $88 \pm 2$ & $87 \pm 2$ & 2.37 \\
SL & $31 \pm 13$ & $15 \pm 4$ & $24 \pm 8$ & 1.77 \\
WASO & $45 \pm 13$ & $31 \pm 4$ & $23 \pm 4$ & 2.25 \\
S1 & $20 \pm 2$ & $22 \pm 2$ & $19 \pm 4$ & 0.36 \\
S2 & $205 \pm 14$ & $213 \pm 16$ & $242 \pm 23$ & 3.32 \\
S3 & $27 \pm 6$ & $32 \pm 10$ & $22 \pm 6$ & 1.00 \\
S4 & $12 \pm 6$ & $9 \pm 6$ & $11 \pm 7$ & 0.19 \\
S1\% & $6 \pm 1$ & $6 \pm 1$ & $5 \pm 1$ & 0.39 \\
S3\% & $8 \pm 2$ & $8 \pm 2$ & $6 \pm 2$ & 0.90 \\
S4\% & $3 \pm 2$ & $3 \pm 2$ & $3 \pm 3$ & 0.38 \\
RD & $2.2 \pm 0.2$ & $2.3 \pm 0.3$ & $2.2 \pm 0.3$ & 0.05
\end{tabular}

All data are expressed as means \pm standard error

TST, Total Sleep Time (min); SE, Sleep Efficiency; SL, Sleep Latency (min); WASO, Wakefulness After Sleep Onset (min); S1-S4, Stage 1-4 Minutes; REM, REM Minutes; S1\%-S4\%, Stage 1-4 Percentages; REM\%, REM Percentage; RL, REM Latency (min); RD, REM Density; NS, Not Significant
Both drinks had significant side effects (Table 6). On the side effect checklist administered to all subjects $7.5 \mathrm{~h}$ after drink ingestion, five subjects reported moderate to severe nausea after the experimental drink and four subjects reported mild to substantial nausea after the control drink. Also after the experimental drink, two subjects complained of mild to substantial diarrhea, two had substantial to severe decreases in appetite, one had moderate anxiety, and a mild level of headache, lightheadedness, difficulty sitting still, muscle stiffness, and trouble concentrating were each reported by one subject. Similarly, after the control drink, two subjects reported mild to substantial diarrhea, one reported a substantial decrease in appetite, three complained of mild to moderate headaches, two suffered mild to moderate muscle stiffness, and mild lightheadedness and difficulty sitting still were each reported by one subject . When tallying these side effects, we took into account the subjects' somatic states before drink ingestion. If the person had the same level or higher of a certain complaint before the drink ingestion that he or she had afterward, that somatic complaint was not attributed to the drink. The somatic side effects attributed to amino acid drinks could easily explain why vigor, elation, and friendliness levels would decrease whether tryptophan was included or not.

\section{Plasma Tryptophan Measures}

The free plasma tryptophan factors of day and time were both significant $\left(\mathrm{F}_{1,7}=34.42, p=.0006\right.$ and $\mathrm{F}_{2,14}=$ $8.59, p=.004$, respectively). The interaction effect between these two factors was also significant $\left(\mathrm{F}_{2,14}=\right.$ $19.32, p=.00009$; Figure 2). A post-hoc Tukey HSD revealed that the experimental day 10:30 P.M. measures were significantly reduced compared with the measures taken on the control day at 2:30 P.M. $(p=.0006)$, 10:30 P.M. $(p=.0002)$, and 7:00 A.M. $(p=.0002)$, and from the measures taken on the experimental day at 2:30 P.M. $(p=.0009)$ and 7:00 A.M. $(p=.0005)$.

\section{DISCUSSION}

Contrary to our first hypothesis based on the study by Nofzinger et al. (1995), no change was found in sleep measures before and after bupropion treatment. Consistent with our second hypothesis, our patients had a significant decrease in RL and $\mathrm{S} 2 \%$ and a significant increase in REM time and REM\% in response to the TFD. As predicted by our third hypothesis, no significant change was seen in the POMS depression subscale or in the HRSD-19 as a result of the TFD. Nevertheless, we did not confirm our hypothesis that the TFD would worsen the subscale scores on the POMS more than the control drink. With regard to the concentration of 
Table 4. Summary and Comparison of Mood Ratings on the While-On-Bupropion Baseline, TFD, and Control Nights at 10:30 P.M.

\begin{tabular}{|c|c|c|c|c|c|}
\hline Mood Ratings & Baseline & TFD & Control & $F_{2,14}$ & $p$ \\
\hline HRSD-19 & $4.38 \pm 1.21$ & $5.00 \pm 1.02$ & $4.12 \pm 0.81$ & 0.38 & NS \\
\hline \multicolumn{6}{|l|}{ POMS } \\
\hline Tension & $4.25 \pm 1.13$ & $5.00 \pm 0.63$ & $4.12 \pm 0.74$ & 0.33 & NS \\
\hline Anger & $2.75 \pm 0.80$ & $2.12 \pm 0.83$ & $1.25 \pm 0.25$ & 1.36 & NS \\
\hline Depression & $5.25 \pm 1.62$ & $3.12 \pm 1.37$ & $3.50 \pm 1.80$ & 3.08 & NS \\
\hline Vigor & $10.00 \pm 2.25$ & $5.88 \pm 1.43 \alpha$ & $5.75 \pm 1.77 \beta$ & 5.02 & .02 \\
\hline Fatigue & $4.00 \pm 1.27$ & $4.12 \pm 1.04$ & $3.38 \pm 1.16$ & 0.33 & NS \\
\hline Confusion & $5.88 \pm 2.06$ & $6.00 \pm 1.72$ & $5.12 \pm 1.27$ & 0.36 & NS \\
\hline Elation & $7.50 \pm 1.95$ & $5.00 \pm 1.28 \alpha$ & $4.25 \pm 1.67 \beta$ & 7.54 & .006 \\
\hline Friendliness & $18.62 \pm 2.64$ & $15.75 \pm 2.66 \alpha$ & $16.12 \pm 2.86 \beta$ & 5.44 & .02 \\
\hline
\end{tabular}

All data are expressed as means \pm standard error

NS, Not Significant

$\alpha$ TFD vs. Baseline, $p<.05 ; \beta$ Control vs. Baseline, $p<.05$

plasma tryptophan, the experimental day 10:30 P.M. measures, which were taken $7.5 \mathrm{~h}$ after TFD administration, were significantly lower than all the other time points on both the control and experimental days. Thus the TFD lowered plasma tryptophan levels as expected.

While the mechanisms of bupropion are not well understood, NE and DA have been implicated with synaptosomal reuptake, in vivo microdialysis, immunoreactivity, electrophysiological, and clinical studies (Ferris and Cooper 1993; Nomikos et al. 1992; Nestler et al. 1990; Cooper et al. 1994; Golden et al. 1988). Nevertheless, bupropion did not affect REM sleep in our study, which is altered by NE reuptake inhibitors and DA agonists. In the rat, NE has been shown to directly inhibit the cholinergic cells of the dorsolateral mesopontine tegmentum (Williams and Reiner 1993). If bupropion enhances NE neurotransmission to the cholinergic neurons in the lateral dorsal mesopontine tegmentum, we might expect REM sleep to be decreased. Support for this comes from studies of NE reuptake inhibitors on sleep. Desipramine, Org 4428, and nortriptyline, for ex-

Table 5. HRSD-19 Scores at 2:30 P.M. and 10:30 P.M. on TFD and Control Nights

\begin{tabular}{lcccc}
\hline & \multicolumn{2}{c}{ TFD } & \multicolumn{2}{c}{ Control } \\
Subject \# & 2:30 P.M. & 10:30 P.M. & 2:30 P.M. & $\mathbf{1 0 : 3 0 ~ P . M . ~}$ \\
\hline 1 & 1 & 0 & 1 & 1 \\
2 & 10 & 3 & 8 & 7 \\
3 & 2 & 6 & 6 & 4 \\
4 & 1 & 4 & 3 & 1 \\
5 & 3 & 9 & 2 & 5 \\
6 & 1 & 4 & 8 & 3 \\
7 & 5 & 6 & 5 & 6 \\
8 & 5 & 8 & 4 & 6 \\
\hline Mean & 3.5 & 5.0 & 4.6 & 4.1 \\
Standard Error & 1.1 & 1.0 & 0.9 & 0.8 \\
\hline
\end{tabular}

ample, all significantly decrease REM time and REM\% (Hishikawa et al. 1965; Ross et al. 1995; Baumann et al. 1983; Dunleavy et al. 1972; van Bemmel et al. 1999; Buysse et al. 1996; Reynolds et al. 1997; Taylor et al. 1999). Perhaps bupropion's main mechanism of action is not NE reuptake inhibition but some other unidentified NE or DA mechanism.

Nofzinger et al. (1995) also had unexpected results with significantly increased REM time and REM\% on bupropion. These results are also different than ours, perhaps due to differences in our subject groups. In Nofzinger's study the mean 24-item HRSD score before treatment was 18.3, while our subjects had a mean 24item HRSD score before treatment of 20.6. The mean final dose of bupropion in the study by Nofzinger (1995) was $428.6 \mathrm{mg}$ /day and subjects had been on bupropion an average of 17.4 weeks. In our study, the mean final dose was $375 \mathrm{mg}$ /day and subjects had been on bupropion an average of 7.4 weeks. These substantial differences in our subject groups may account for the disparate results of our studies. The lack of fundamental understanding regarding bupropion's mechanism of action makes further speculation difficult.

Depleting 5-HT levels with the TFD significantly enhanced REM sleep patterns in our study. This finding is compatible with the hypothesis that decreases in serotonin neurotransmission disinhibit REM sleep. We must keep in mind, however, that our evidence for central 5-HT depletion is not direct. We are assuming that tryptophan depletion in plasma limits the rate of 5-HT production in the brain. There is evidence for this from studies utilizing slice preparations. One such study showed that serotonergic neurons in slice preparations use up their 5-HT stores within $2 \mathrm{~h}$ after tryptophan is depleted from the superfusion solution (Lin et al. 1969). Another study showed that 5-HT release in brain slices decreases when the slice preparation is superfused with a solution of large neutral amino acids minus tryptophan (Schaechter and Wurtman 1990). 
Table 6. Side Effects Checklist Scores at 2:30 P.M., 10:30 P.M., and 7 A.M. during the TFD and Control Days

\begin{tabular}{|c|c|c|c|c|c|c|}
\hline Subject \# & $\begin{array}{c}\text { TFD } \\
\text { 2:30 P.M. }\end{array}$ & $\begin{array}{c}\text { TFD } \\
\text { 10:30 P.M. }\end{array}$ & $\begin{array}{c}\text { TFD } \\
\text { 7:00 A.M. }\end{array}$ & $\begin{array}{l}\text { Control } \\
\text { 2:30 P.M. }\end{array}$ & $\begin{array}{c}\text { Control } \\
\text { 10:30 P.M. }\end{array}$ & $\begin{array}{l}\text { Control } \\
\text { 7:00 A.M. }\end{array}$ \\
\hline 1 & 4 & 15 & 5 & 2 & 15 & 9 \\
\hline 2 & 10 & 11 & 10 & 6 & 9 & 6 \\
\hline 3 & 3 & 9 & 1 & 2 & 0 & 0 \\
\hline 4 & 9 & 16 & 10 & 10 & 5 & 10 \\
\hline 5 & 7 & 7 & 1 & 4 & 4 & 2 \\
\hline 6 & 1 & 3 & 1 & 0 & 3 & 1 \\
\hline 7 & 11 & 22 & 7 & 9 & 18 & 9 \\
\hline 8 & 4 & 6 & 2 & 13 & 6 & 1 \\
\hline Mean & 6.1 & 11.1 & 4.6 & 5.8 & 7.5 & 4.8 \\
\hline Standard Error & 1.3 & 2.2 & 1.4 & 1.6 & 2.2 & 1.5 \\
\hline
\end{tabular}

Overall, the effects of the TFD here are very similar to those reported by our laboratory in Bhatti et al. (1998) with normal adult males and in Moore et al. (1998) with SSRI treated patients: facilitation of REM sleep without significant effects on depressive symptoms. Bupropion's mode of action as an antidepressant is possibly unaffected by manipulations in the 5-HT system. Partially remitted patients on bupropion and fully remitted patients on SSRIs do not "relapse" in response to TFDs (Moore et al. 1998). In contrast, many partially remitted patients on SSRIs did "relapse" into depression following TFD administration (Delgado et al. 1990, 1991, 1999). Differences between the Delgado and Moore studies may explain these discrepancies. The Moore et al. (1998) study used subjects in full remission with HRSD-17 scores of below 7 for at least two months with a total treatment time of two to 13 months, while the Delgado et al. $(1990,1999)$ studies used patients who were only partially remitted with scores of less than 18 on the 25-item HRSD for two weeks with a total treatment time of four to 10 weeks. (Further discussions of discrepancies in TFD studies can be found in Moore et al. 1998, 2000, 2001.) Our current study uses partially remitted patients with two weeks of HRSD-17 scores below 11 and a total of five to 11 weeks of treatment, yet we find no "depressive relapse" in response to tryptophan depletion.

The failure of the TFD to affect depression ratings in the current study suggests several interpretations. One interpretation is that bupropion's antidepressant effects do not depend upon serotonergic mechanisms. This idea is supported by in vitro and electrophysiological studies which show that bupropion has little to no effect on the serotonin system (Cooper et al. 1994; Feighner 1999; Horst and Preskorn 1998; Stahl 1997). A second is that the TFD-induced relapse occurs only in patients who are early in their treatment or who still remain moderately depressed (see discussion by Moore et al. 1998). A third possibility is that our subject group was composed of individuals resistant to TFD-induced relapse. Based on a recent "mega-analysis" of individual subject data from six TFD studies, statistically significant predictors of clinical relapse were recurrent depressive episodes, female gender, prior exposure to SSRI treatment, and previous suicidal thoughts or attempts (Booij et al. in press). In our study, two of our subjects had all four predictors, two had two of the predictors, one had one predictor, and three had no predictors. The low number of TFD clinical relapse predictors among several of our subjects may also have contributed to the lack of effect the TFD had on depression ratings in this study. In addition to not having many clinical relapse predictors, our subjects may not be genetically predisposed to a depressive response after tryptophan depletion. A recent study by Moreno et al. (2002) showed an association between a particular genotype in the promoter region of the serotonin trans-

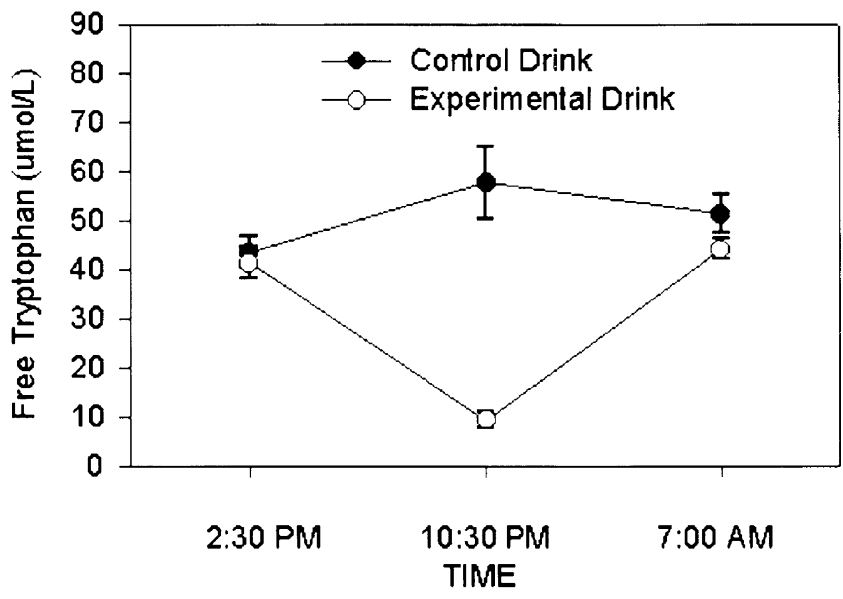

Figure 2. Mean free plasma tryptophan levels at 2:30 P.M., 10:30 P.M., and 7 A.M. on the control and experimental days (values given are means \pm SEM, $n=8$ ) with a significant interaction effect between the factors of day and time $\left(\mathrm{F}_{2,14}=\right.$ $19.32, p=.00009$ ) 
porter gene and a depressive response to tryptophan depletion. Another possible interpretation is that since patients were only in partial remission, rather than full remission, and it has been shown that TFDs do not enhance the severity of depressive symptoms in symptomatic depressed patients (Delgado et al. 1994; Neumeister et al. 1997), we may not have been able to see a depressive response in our study. Delgado et al. (1990, 1991, 1999), however, used partially remitted patients on antidepressants with scores on the 25-item HRSD that were quite similar to the scores our subjects had on the 24-item HRSD and they found a depressive response. This can be most clearly seen when comparing Table 1 from the Delgado et al. (1990) paper with Table 1 in this paper. Pretryptophan depletion scores in Delgado et al. (1990) range from 2 to 19 with an average score of 8.4. Pretryptophan depletion scores in our study range from 2 to 11 with an average score of 6.9. The other two studies by Delgado et al. (1991, 1999) with partially remitted patients do not list the HRSD scores but have very similar inclusion criteria regarding the HRSD scores. One final interpretation is suggested by Neumeister et al. (1998), which showed that tryptophan depletion prevented depressive relapses in patients who responded favorably to sleep deprivation after the recovery night of sleep. This study suggests that tryptophan depletion may actually decrease depressive symptoms in some people. The data in Table 5 reveal that six of our eight subjects had an increase in their HRSD-19 scores in response to the TFD. These six subjects certainly did not have a decrease in depressive symptoms, but perhaps the other two did have favorable responses. The timescales in the two studies, however, are not comparable and make it difficult to come to this conclusion. The positive effects of tryptophan depletion in the Neumeister et al. (1998) study occurred almost $24 \mathrm{~h}$ later rather than $7.5 \mathrm{~h}$ later as in our study. After $24 \mathrm{~h}$, subjects in our study who had an increase in their HRSD scores had already returned to their preTFD levels.

Our study has limitations. Its design was not optimal. The tryptophan challenge, while-on-bupropion, baseline night was not blinded as the TFD and control nights were. This may have resulted in some bias, on the part of the patients and objective raters, in the mood ratings for that night. Also, we did not measure mood ratings at all the time points on the baseline night that we did on the TFD and control nights. This makes it difficult to interpret our diurnal results since the natural variations in mood for our partially remitted patients were not documented.

In summary, we did not find that the TFD reversed the antidepressant effects of bupropion in partially remitted patients even though it significantly enhanced REM sleep. Plasma tryptophan levels also dropped as a result of the TFD and increased in response to the control drink.

\section{ACKNOWLEDGMENTS}

We gratefully acknowledge the technical assistance of Arlene Schlosser, Lesley Wetherell, Anna DeModena, and Sheila Neely. This research was supported by the UCSD MHCRC (MH30914), a VA Merit Award (JCG), a NIMH R01 (MH57134), and the UCSD General Clinical Research Center (Michael Ziegler, MD, director; M01-RR00827).

\section{REFERENCES}

Abbott FV, Etienne P, Franklin KB, Morgan MJ, Sewitch MJ, Young SN (1992): Acute tryptophan depletion blocks morphine analgesia in the cold-pressor test in humans. Psychopharmacology (Berl) 108:60-66

Ascher JA, Cole JO, Colin J-N, Feighner JP, Ferris RM, Fibiger HC, Golden RN, Martin P, Potter WZ, Richelson E, Sulser F (1995): Bupropion: A review of its mechanism of action. J Clin Psychiatry 56:395-401

Baumann P, Gaillard J-M, Perey M, Justafre J-C, Le P (1983): Relationships between brain concentrations of desipramine and paradoxical sleep inhibition in the rat. J Neural Transm 56:105-116

Benca RM, Obermeyer WH, Thisted RA, Gillin JC (1992): Sleep and psychiatric disorders: A meta-analysis. Arch Gen Psychiatry 49:651-668

Benkelfat C, Ellenbogen MA, Dean P, Palmour RM, Young SN (1994): Mood-lowering effect of tryptophan depletion. Enhanced susceptibility in young men at genetic risk for major affective disorders. Arch Gen Psychiatry 51:687-697

Bhatti T, Gillin JC, Seifritz E, Moore P, Clark C, Golshan S, Stahl S, Rapaport M, Kelsoe J (1998): Effects of a tryptophan-free amino acid drink challenge on normal human sleep electroencephalogram and mood. Biol Psychiatry 43:52-59

Biggio G, Fadda F, Fanni P, Tagliamonti A, Gessa GL (1974): Rapid depletion of serum tryptophan, serotonin, and 5-hydroxyindoleacetic acid by a tryptophan-free diet. Life Sci 14:1321-1329

Booij L, Van der Does W, Benkelfat C, Bremner JD, Cowen PJ, Fava M, Gillin JC, Leyton M, Moore P, Smith KA, Van der Kloot WA (in press): Predictors of mood response to acute tryptophan depletion: A reanalysis. Neuropsychopharmacology

Bremner JD, Innis RB, Salomon RM, Staib LH, Ng CK, Miller HL, Bronen RA, Krystal JH, Duncan J, Rich D, Price LH, Malison R, Dey H, Soufer R, Charney DS (1997): Positron emission tomography measurement of cerebral metabolic correlates of tryptophan depletion-induced depressive relapse. Arch Gen Psychiatry 54:364-374

Buysse DJ, Reynolds CF 3rd, Hoch CC, Houck PR, Kupfer DJ, Mazumdar S, Frank S (1996): Longitudinal effects of nortriptyline on EEG sleep and the likelihood of recurrence in elderly depressed patients. Neuropsychopharmacology 14:243-252

Cooper BR, Wang CM, Cox RF, Norton R, Shea V, Ferris RM (1994): Evidence that the acute behavioral and electrophysiological effects of bupropion are mediated by a noradrenergic mechanism. Neuropsychopharmacology 11:133-141 
Delgado PL, Charney DS, Price LH, Aghajanian GK, Landis H, Heninger GR (1990): Serotonin function and the mechanism of antidepressant action. Reversal of antidepressant-induced remission by rapid depletion of plasma tryptophan. Arch Gen Psychiatry 47:411-418

Delgado PL, Miller HL, Salomon RM, Licinio J, Krystal JH, Moreno FA, Heninger GR, Charney DS (1999): Tryptophan-depletion challenge in depressed patients treated with desipramine or fluoxetine: Implications for the role of serotonin in the mechanism of antidepressant action. Biol Psychiatry 46:212-220

Delgado PL, Price LH, Miller HL, Salomon RM, Licinio J, Krystal JH, Heninger GR, Charney DS (1991): Rapid serotonin depletion as a provocative challenge test for patients with major depression: Relevance to antidepressant action and the neurobiology of depression. Psychopharm Bull 27:321-330

Delgado PL, Price LH, Miller HL, Salomon RM, Aghajanian GK, Heninger GR, Charney DS (1994): Serotonin and the neurobiology of depression. Effects of tryptophan depletion in drug-free depressed patients. Arch Gen Psychiatry 51:865-874

Denckla WD, Dewey HK (1967): The determination of tryptophan in plasma, liver, and urine. J Lab Clin Med 69:160-169

Dunleavy DLF, Brezinova V, Oswald I, Maclean AW, Tinker M (1972): Changes during weeks in the effects of tricyclic drugs on the human sleeping brain. Br J Psychiatry 120:663-672

Ellenbogen MA, Young SN, Dean P, Palmour RM, Benkelfat C (1996): Mood response to acute tryptophan depletion in healthy volunteers: Sex differences and temporal stability. Neuropsychopharmacology 15:465-474

Ellenbogen MA, Young SN, Dean P, Palmour RM, Benkelfat C (1999): Acute tryptophan depletion in healthy young women with a family history of major affective disorder. Psychol Med 29:35-46

Feighner JP (1999): Mechanism of action of antidepressant medications. J Clin Psychiatry 60:S4-11

Ferris RM, Cooper BR (1993): Mechanism of antidepressant activity of bupropion. J Clin Psychiatry Monograph 11:2-14

Golden RN, Markey SP, Risby ED, Rudorfer MV, Cowdry RW, Potter WZ (1988): Antidepressants reduce whole-body norepinephrine turnover while enhancing 6-hydroxymelatonin output. Arch Gen Psychiatry 45:150-154

Hamilton M (1967): Development of a rating scale for primary depressive illness. Br J Soc Clin Psychol 6:278-296

Hishikawa Y, Nakai K, Ida H, Kaneko Z (1965): The effect of imipramine, desmethylimipramine and chlorpromazine on the sleep-wakefulness cycle of the cat. EEG Clin Neurophysiol 19:518-521

Horst DW, Preskorn SH (1998): Mechanisms of action and clinical characteristics of three atypical antidepressants: venlafaxine, nefazodone, bupropion. J Aff Dis 51:237-254

Jones BE (1991): Paradoxical sleep and its chemical/structural substrates in the brain. Neuroscience 40:637-656

Klaassen T, Riedel WJ, van Someren A, Deutz NE, Honig A, van Praag HM (1999): Mood effects of 24-hour tryptophan depletion in healthy first-degree relatives of patients with affective disorders. Biol Psychiatry 46: 489-497

Landolt HP, Schnierow BJ, Kelsoe JR, Rapaport MH, Gillin JC (2000): Phenelzine-induced suppression of REM sleep can be reversed by rapid tryptophan depletion. Sleep 23:S34-35

Leyton M, Gharirian AM, Young SN, Palmour RM, Blier P, Helmers KF, Benkelfat C (2000): Depressive relapse following acute tryptophan depletion in patients with major depressive disorder. J Psychopharmacol 14:284287

Leyton M, Young SN, Blier P, Ellenbogen MA, Palmour RM, Ghadirian A-M, Benkelfat C (1997): The effect of tryptophan depletion on mood in medication-free, former patients with major affective disorders. Neuropsychopharmacology 16:294-297

Lin RC, Costa E, Neff NH, Wang CT, Ngai SH (1969): In vivo measurement of 5-hydroxytryptamine turnover rate in the rat brain from the conversion of C14-tryptophan to C14-5-hydroxytryptamine. J Pharmacol Exp Ther 170:232-238

Luebke JI, Greene RW, Semba K, Kamondi A, McCarley RW, Reiner PB (1992): Serotonin hyperpolarizes cholinergic low-threshold burst neurons in the rat laterodorsal tegmental nucleus in vitro. Proc Natl Acad Sci USA 89:743747

Maes M, Meltzer HY (1995): The serotonin hypothesis of major depression. In Bloom FE, Kupfer DJ (eds), Psychopharmacology: The Fourth Generation of Progress. New York, Raven Press, pp 933-944

McCarley RW (1982): REM sleep and depression: Common neurobiological control mechanisms. Am J Psychiatry 139:565-570

McGinty DJ, Drucker-Colin RR (1982): Sleep mechanisms: Biology and control of REM sleep. Neurobiology 23:391-436

McNair DM, Lorr D, Droppelman LF (1981): Manual for the Profile of Mood States. San Diego, Educational Testing Services

Moja EA, Stoff DM, Gessa GL, Castoldi D, Assereto R, Tofanetti O (1988): Decrease in plasma tryptophan after tryptophan-free amino acid mixtures in man. Life Sci 42:1551-1556

Moore P, Gillin JC, Bhatti T, DeModena A, Seifritz E, Clark C, Stahl S, Rapaport M, Kelsoe J (1998): Rapid tryptophan depletion, sleep electroencephalogram, and mood in men with remitted depression on serotonin reuptake inhibitors. Arch Gen Psychiatry 55:534-539

Moore PJ, Gillin JC, Landolt H-P, Rapaport M, Kelsoe J (2001): Letter in reply to (The mood lowering effect of tryptophan depletion: possible explanation for discrepant findings). Arch Gen Psychiatry 58:201-202

Moore P, Landolt H-P, Seifritz E, Clark C, Bhatti T, Kelsoe J, Rapaport M, Gillin JC (2000): Clinical and physiological consequences of rapid tryptophan depletion. Neuropsychopharmacology 23:601-622

Moreno FA, Rowe DC, Kaiser B, Chase D, Michaels T, Gelernter J, Delgado PL (2002): Association between a serotonin transporter promotor region polymorphism and mood response during tryptophan depletion. Mol Psychiatry 7:213-216 
Nestler EJ, McMahon A, Sebban EL, Tallman JF, Duman RS (1990): Chronic antidepressant administration decreases the expression of tyrosine hydroxylase in the rat locus ceruleus. Proc Natl Acad Sci USA 87:7522-7526

Neumeister A, Praschak-Rieder N, Hesselmann B, Vitouch O, Rauh M, Barocka A, Kasper S (1997): Rapid tryptophan depletion in drug-free depressed patients with seasonal affective disorder. Am J Psychiatry 154:11531155

Neumeister A, Praschak-Rieder N, Hesselmann B, Vitouch O, Rauh M, Barocka A, Tauscher J, Kasper S (1998): Effects of tryptophan depletion in drug-free depressed patients who respond to total sleep deprivation. Arch Gen Psychiatry 55:167-172

Nofzinger EA, Reynolds CF, Thase ME, Frank E, Jennings JR, Fasiczka AL, Sullivan LR, Kupfer DJ (1995): REM sleep enhancement by bupropion in depressed men. Am J Psychiatry 152:274-276

Nomikos GG, Damsma G, Wenkstern D, Fibiger HC (1992): Effects of chronic bupropion on interstitial concentrations of dopamine in rat nucleus accumbens and striatum. Neuropsychopharmacology 7:7-14

Paul IA, Nowak G, Layer RT, Popik P, Skolnick P (1994): Activation of the N-methyl-D-aspartate receptor complex following chronic antidepressant treatments. J Pharmacol Exp Ther 269:95-102

Quintin P, Benkelfat C, Launay JM, Arnulf I, PointereauBellenger A, Barbault S, Alvarez JC, Varoquaux O, Perez-Diaz F, Jouvent R, Leboyer M (2001): Clinical and neurochemical effect of acute tryptophan depletion in unaffected relatives of patients with bipolar affective disorder. Biol Psychiatry 50:184-190

Reynolds CF 3rd, Buysse DJ, Brunner DP, Begley AE, Dew MA, Hoch CC, Hall M, Houck PR, Mazumdar S, Perel JM, Kupfer DJ (1997): Maintenance nortriptyline effects on electroencephalographic sleep in elderly patients with recurrent major depression: double-blind, placeboand plasma-level-controlled evaluation. Biol Psychiatry 42:560-567

Rechtschaffen A, Kales AA (1968): A Manual of Standard- ized Terminology, Techniques and Scoring system for Sleep Stages of Human Subjects. Washington DC, Public Health Services

Ross RJ, Gresch PJ, Ball WA, Sanford LD, Morrison AR (1995): REM sleep inhibition by desipramine: evidence for an $\alpha-1$ adrenergic mechanism. Brain Res 701:129-134

Schaechter JD, Wurtman RJ (1990): Serotonin release varies with brain tryptophan levels. Brain Res 532:203-210

Spillman MK, Van der Does AJW, Rankin MA, Vuolo RD, Alpert JE, Nierenberg AA, Rosenbaum JF, Hayden D, Schoenfeld D, Fava M (2001): Tryptophan depletion in SSRI recovered depressed outpatients. Psychopharmacology (Berl) 155:123-127

Stahl SM (1997): Psychopharmacology of Antidepressants. London, Martin Dunitz Ltd

Stahl SM (2000): Essential Psychopharmacology: Neuroscientific Basis and Practical Applications, 2nd ed. New York, Cambridge University Press

Taylor MP, Reynolds CF 3rd, Frank E, Dew MA, Mazumdar S, Houck PR, Kupfer DJ (1999): EEG sleep measures in later-life bereavement depression: a randomized, double-blind, placebo-controlled evaluation of nortriptyline. Am J Geriatr Psychiatry 7:41-47

Van Bemmel AL, Vermeeren MT, Ruigt G, Sennef C (1999): The acute effects of the noradrenaline reuptake inhibitor Org 4428 on EEG sleep in health volunteers. Neuropsychobiology 40:107-114

Voderholzer U, Hornyak M, Thiel B, Huwig-Poppe C, Kieman A, Konig A, Backhaus J, Riemann D, Berger M, Hohagen F (1998): Impact of experimentally induced serotonin deficiency by tryptophan depletion on sleep EEG in healthy subjects. Neuropsychopharmacology 18:112-124

Williams JA, Reiner PB (1993): Noradrenaline hyperpolarizes identified rat mesopontine cholinergic neurons in vitro. J Neurosci 13:3878-3883

Young SN, Smith SE, Pihl RO, Ervin FR (1985): Tryptophan depletion causes a rapid lowering of mood in normal males. Psychopharmacology (Berl) 87:173-177 